Zeolites and Related Materials: Trends, Targets and Challenges

Proceedings of $4^{\text {th }}$ International FEZA Conference

A. Gedeon, P. Massiani and F. Babboneau (Editors)

(C) 2008 Elsevier B.V. All rights reserved.

\title{
Polystyrene modified hybrid materials based on ordered mesoporous silica
}

R. van Grieken, G. Morales, A. Martín and F. Martínez

Department of Chemical and Environmental Technology, ESCET,Universidad Rey Juan Carlos, C/ Tulipán s/n, 28933 Móstoles, Madrid, Spain

Published on

Studies in Surface Science and Catalysis 174A (2008) 345-348

doi:10.1016/S0167-2991(08)80213-3 


\title{
Polystyrene modified hybrid materials based on ordered mesoporous silica
}

\author{
R. van Grieken, G. Morales, A. Martín and F. Martínez \\ Department of Chemical and Environmental Technology, ESCET,Universidad Rey Juan \\ Carlos, C/ Tulipán s/n, 28933 Móstoles, Madrid, Spain
}

\begin{abstract}
Organically-modified mesoporous silica materials have been prepared by direct cocondensation of styrylethyltrimethoxysilane (STETMOS) and tetraethylorthosilicate (TEOS) in one-pot synthesis. The polimerizable nature of the styryl-containing precursor induces the formation of anchored polystyrene blocks over the silica surface, which are amenable to be functionalized with acid groups via sulfonation. The resultant organosulfonic-modified mesostructured silica materials have exhibited hexagonal longrange mesoscopic arrangement with extended surface areas and narrow mean pore size distributions. The acid capacity of these materials was assessed on the acid-catalyzed reaction test of anisole acylation with acetic anhydride.
\end{abstract}

Keywords: SBA-15, mesoporous, polystyrene, anisole, acylation.

\section{Introduction}

In the last few years, the field of hybrid organic-inorganic mesoporous materials has been an issue of extensive research. The combination of the extended surface area of inorganic silica-based mesoporous materials and the enormous functionability and versatility of polymeric organic moieties leads to hybrid materials with potential applications in catalysis, separation processes and other related areas, taking advantage of the symbiosis between the organic and inorganic components [1]. In this context, the incorporation of covalently attached polystyrene-type moieties on the pore walls of mesoporous silicas allows the production of highly acid hybrid materials by sulfonation of said styrenic functionalities.

The activity of these materials has been evaluated on the anisole acylation with acetic anhydride for the production of methoxyacetophenones (MAPs, Scheme 1a), which are key intermediates for the preparation of several pharmaceuticals and fragrances. This catalytic test has been commonly used for the assessment of a wide variety of acid solid catalysts [2].

\section{Experimental}

The organically-modified materials were prepared via co-condensation as follows. A solution of tri-block copolymer Pluronic $123\left(\mathrm{EO}_{20} \mathrm{PO}_{70} \mathrm{EO}_{20}\right)$ in $1.9 \mathrm{M} \mathrm{HCl}$ was prepared at RT. Then, the solution was heated to $40^{\circ} \mathrm{C}$ before the silica source (TEOS) and the styryl-containing organosilane (STETMOS; Scheme $1 \mathrm{~b}$ ) were added at different STETMOS/TEOS molar ratios $(5,10,20$, and 30\%, corresponding to samples denoted as ST5, ST10, ST20, and ST-30, respectively). After stirring $20 \mathrm{~h}$ at $40^{\circ} \mathrm{C}$, the solution was aged under static conditions at $100^{\circ} \mathrm{C}$ for $24 \mathrm{~h}$. Solid materials were recovered by filtration and air-dried overnight. The surfactant removal was performed by ethanolwashing and subsequent mild thermal treatment $\left(5 \mathrm{~h}, 150^{\circ} \mathrm{C}\right)$. 
a)<smiles></smiles>

Anisole<smiles>COc1ccc(C(C)=O)cc1</smiles>

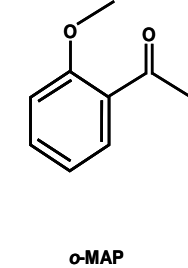

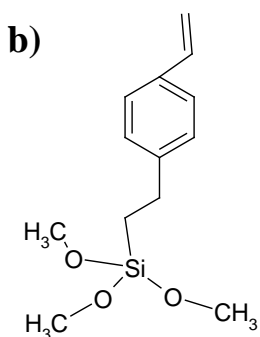

Scheme 1. a) Simplified reaction scheme for the acylation of anisole with acetic anhydride. b) Molecular structure of styrylethyltrimethoxysilane (STETMOS).

The resultant mesoporous organic-inorganic hybrid materials were successfully sulfonated following the procedure described elsewhere [3]. Polystyrene modified mesoporous hybrid materials were structurally characterized by means of X-ray powder diffraction, nitrogen adsoption-desorption isotherms at 77K, and TEM microscopy. The organic content was quantified by thermogravimetric analyses. ${ }^{29} \mathrm{Si}$ and ${ }^{13} \mathrm{C}$ solid state MAS-NMR and DR-UV-Vis spectroscopies were used to characterize the environment of the carbon and silicon nuclei. The acid capacity of the organosulfonic-modified materials was determined by titration and elemental analyses. Catalytic tests were carried out in a teflon-lined stainless steel stirred autoclave equipped with temperature controller and pressure gauge. Reaction time was fixed at 5 hours and stirring at 500 rpm to avoid diffusional limitations. Methoxyacetophenones were the only identified products and were quantified by GC using a GC-3900 Varian chromatograph equipped with a CP-SIL 8 CB capillary column (30 m x $0.25 \mathrm{~mm}$ ) and a FID detector.

\section{Results and discussion}

Table 1 summarises the textural properties of the polymer-modified mesoporus materials. With the purpose of comparison, purely siliceous SBA-15 is also included. The increase of the STETMOS organosilane content is accompanied with the decrease of BET surface area and pore volume. $\mathrm{N}_{2}$ adsorption-desorption isotherms exhibited a broader H-1-type hysteresis loop with the increase of the organosilane precursor, leading to wider pore size distributions centred at reduced mean pore sizes. XRD patterns illustrated in Figure 1a evidenced the typical low-angle diffraction pattern of hexagonal $p 6 \mathrm{~mm}$ symmetry. This hexagonal arrangement of mesoporous SBA-15-type materials was also confirmed by TEM. Figure 1b shows micrographs taken from ST-20 sample.

Table 1. Textural properties and organic incorporation of mesoporous composite materials.

\begin{tabular}{cccccc}
\hline Sample / Type & $\begin{array}{c}\mathrm{S}_{\mathrm{BET}} \\
\left(\mathrm{m}^{2} / \mathrm{g}\right)\end{array}$ & $\begin{array}{c}\mathrm{D}_{\mathrm{p}}{ }^{\mathrm{a}} \\
(\AA)\end{array}$ & $\begin{array}{c}\mathrm{V}_{\mathrm{t}}{ }^{\mathrm{a}} \\
\left(\mathrm{cm}^{3} / \mathrm{g}\right)\end{array}$ & $\begin{array}{c}d_{100}{ }^{\mathrm{b}} \\
(\AA)\end{array}$ & $\begin{array}{c}\text { Final incorporation }{ }^{\mathrm{c}} \\
(\%)\end{array}$ \\
\hline SBA-15 / Silica & 675 & 89 & 1.06 & 95 & - \\
\hline ST5 / Hybrid (5\%) & 625 & 70 & 0.90 & 85 & 6.3 \\
ST10 / Hybrid (10\%) & 573 & 63 & 0.62 & 81 & 11.0 \\
ST20 / Hybrid (20\%) & 374 & 59 & 0.44 & 83 & 17.9 \\
ST30 / Hybrid (30\%) & 188 & 59 & 0.25 & 81 & 20.2 \\
\hline
\end{tabular}

${ }^{a}$ Pore size and total pore volume calculated by BJH method from the adsorption branch. ${ }^{\mathrm{b}} d(100)$ spacing, measured from small-angle XRD. ${ }^{c}$ Organic incorporation by final STETMOS/TEOS ratio calculated by Solid-state ${ }^{29}$ Si MAS-NMR as $\Sigma$ T $/ \Sigma \mathrm{T}+\Sigma \mathrm{Q}$ 

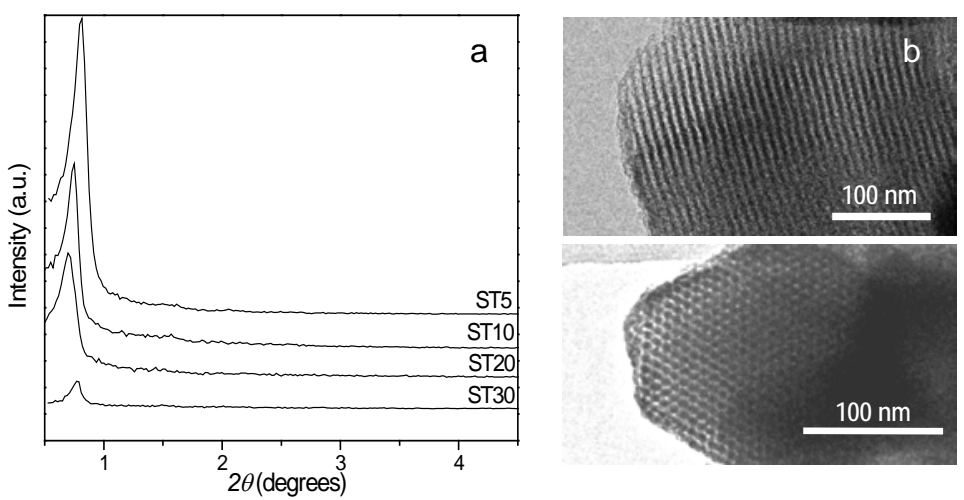

Figure 1. (a) X-ray diffraction patterns of mesoporous organic-silica composite materials; and (b) TEM images of cross and longitudinal section for ST20 sample.

The reactivity of styryl terminal groups of the organosilane precursor provides the formation of accessible polystyrene-type organic moieties on the silica surface. This fact can be demonstrated by means of DR-UV-Vis and solid-state ${ }^{13} \mathrm{C}$ CP MAS-NMR. DRUV-Vis spectra show that bands at $280 \mathrm{~nm}$ corresponding to non-polymerised styrenic olefin, as seen in SBA-15 silica sample impregnated with free liquid STETMOS, disappears in all the ST hybrid materials (Figure 2a). This band is displaced to lower wavelengths $(255 \mathrm{~nm})$ corresponding to aromatic rings with no olefin nearby. Solidstate ${ }^{13} \mathrm{C}$ CP MAS-NMR also evidences the absence of the signal at $113 \mathrm{ppm}$, which is assignable to the terminal olefin of the styrenic group of the organosilane precursor (spectra of ST20 sample, Figure 2b). Other signals associated with the aromatic ring of the organosilane precursor and the remaining surfactant molecules were determined. Solid-state ${ }^{29} \mathrm{Si}$ MAS-NMR demonstrated the presence of organic moieties chemically attached to the silica via Si-C bonds, evidencing a reduction of the organic incorporation yield for samples with a STETMOS/TEOS molar ratio in synthesis higher than $20 \%$ (Table 1).
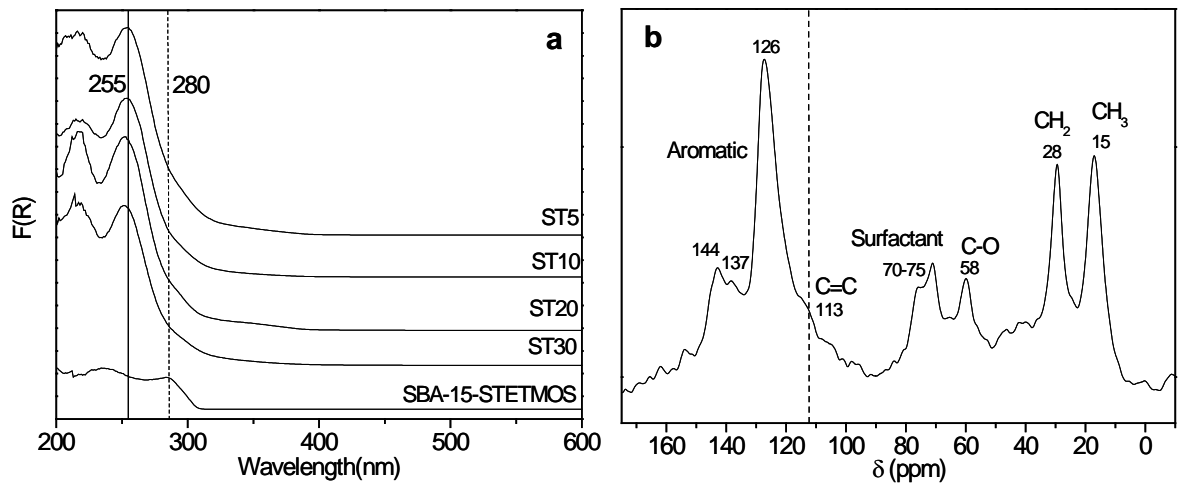

Figure 2. a) DR-UV-VIS spectra of mesoporous organic-silica composite materials and SBA-15 impregnated with STETMOS; b) ${ }^{13} \mathrm{C}$ CP MAS-NMR spectra of ST20 sample.

Table 2 shows the parameters related to the acidic properties of the sulfonatedmesoporous hybrid materials and their catalytic activity for the acylation of anisole with acetic anhydride. Acid-exchange capacities estimated by acid-base titration after 
cationic exchange ranges from 0.28 to 1.45 meq of $\mathrm{H}^{+} / \mathrm{g}$. Sulfonation yield is clearly dependent on the organosilane content up to values corresponding to S-ST-20 sample, which exhibited the highest acid capacity $\left(1.7 \mathrm{mmol} \mathrm{H}^{+} / \mathrm{g}\right)$ and sulfur content (1.66 meq S/g). However, a higher organosilane loading, as in ST-30 sample, did not provide an increase in the acid capacity. This is attributed to its lower surface area and less concentration of surface polystyrene-type moieties amenable to be sulfonated. It is also noteworthy for the catalytic application that the accessibility of immobilized sulfonic acid sites seems to be not limited by the organic loading of the hybrid material.

Table 2. Acid properties and catalytic activity of the sulfonated-mesoporous hybrid materials.

\begin{tabular}{c|ccc|cc}
\hline \multirow{3}{*}{ Sample } & \multicolumn{3}{|c|}{ Acid Capacity } & \multicolumn{2}{c}{ Catalytic activity $^{\mathrm{d}}$} \\
\cline { 2 - 6 } & $\begin{array}{c}\text { Titration }^{\mathrm{a}} \\
\left(\mathrm{meq} \mathrm{H}^{+} / \mathrm{g}\right)\end{array}$ & $\begin{array}{c}\text { S content }^{\mathrm{b}} \\
\text { (meq S/g) }\end{array}$ & $\begin{array}{c}\text { Accessibility } \\
\text { (\%) }\end{array}$ & $\begin{array}{c}\text { Conversion } \\
(\%)\end{array}$ & $\begin{array}{c}\text { Specific } \\
\text { activity }^{\mathrm{e}}\end{array}$ \\
\hline S-ST5 & 0.28 & 0.22 & $\sim 100$ & 0.7 & 1.22 \\
S-ST10 & 0.96 & 0.95 & $\sim 100$ & 7.0 & 3.57 \\
S-ST20 & 1.70 & 1.66 & $\sim 100$ & 18.1 & 5.21 \\
S-ST30 & 1.45 & 1.42 & $\sim 100$ & 16.0 & 5.40 \\
\hline SAC-13 & 0.14 & 0.16 & 87 & 16.1 & 56.3 \\
Amberlyst-15 & 4.80 & - & - & 34.8 & 3.68 \\
\hline
\end{tabular}

${ }^{a}$ Estimated by cationic-exchange in saturated $\mathrm{NaCl}$ solution followed by titration with $\mathrm{NaOH} 0.01 \mathrm{M}$. ${ }^{\mathrm{b}}$ Sulfur content by elemental analysis. ${ }^{\mathrm{c}}$ Ratio between titration and sulfur content values. ${ }^{\mathrm{d}}$ Reaction conditions: $150^{\circ} \mathrm{C}, 5 \mathrm{~h}$, anisole/catalyst mass ratio of 80 , equimolar acylating agent:substrate mixture. ${ }^{\text {e }}$ Specific activity as reacted mmol of anisole per mmol of acid site.

Catalytic results of the series of S-ST materials indicate the best anisole conversion for the S-ST-20 sulfonated-mesoporous hybrid material (ca. 18\%), which is in agreement with its highest acid capacity. With the purpose of comparison, other commercial heterogeneous acid catalysts were assayed. The catalytic activity of S-ST20 was higher than that shown by SAC-13, which is considered an extremely active acid catalyst based on a perfluorosulfonic Nafion ${ }^{\circledR}$ resin supported over amorphous silica [4]. The catalytic test with the polystyrene-based sulfonic-acid resin (Amberlyst ${ }^{\circledR}-15$ ) yielded a remarkable conversion of anisole, although its use is normally limited to $120^{\circ} \mathrm{C}$ due to thermal decomposition of the polymeric resin. Additionally, in terms of specific activity (anisole converted per acid site), S-ST-20 mesoporous material provides better results than Amberlyst ${ }^{\circledR}-15$.

\section{Conclusions}

ST-mesoporous organic-silica composite materials synthesized by co-condensation using a styryl-containing organosilane precursor have allowed a valuable incorporation of polystyrene moieties on the mesostructured silica surface, which can be readily functionalized with sulfonic acid groups. In particular, the sulfonated S-ST-20 material has exhibited promising catalytic activities in the acid-catalyzed reaction of anisole acylation, especially as compared to commercial SAC-13 and Amberlyst-15 catalysts.

\section{References}

[1] F. Hoffmann, M. Cornelius, J. Morell, M. Fröba, Angew. Chem. Int. Ed. 45 (2006) 3216.

[2] V.R. Sarsani, C.J. Lyon, K.W. Hutchenson, M.A. Harmer, J. Catal 245 (2007) 184.

[3] H.S. Makowski, R.D. Lundberg, G.H. Singhal, US 3870841 (1975).

[4] A. Heidekum, M. A. Harmer, W. F. Hölderich, J. Catal. 188 (1999) 230-232. 